\title{
Article \\ Green Light Improves Photosystem Stoichiometry in Cucumber Seedlings (Cucumis sativus) Compared to Monochromatic Red Light
}

\author{
Nicholas B. Claypool (D) and J. Heinrich Lieth *
}

Plant Sciences, University of California, Davis, CA 95616, USA; nbclaypool@gmail.com

* Correspondence: jhlieth@ucdavis.edu

check for updates

Citation: Claypool, N.B.; Lieth, J.H. Green Light Improves Photosystem Stoichiometry in Cucumber Seedlings (Cucumis sativus) Compared to Monochromatic Red Light. Plants 2021, 10, 824. https://doi.org/ $10.3390 /$ plants10050824

Academic Editor: Valeria Cavallaro

Received: 29 March 2021

Accepted: 18 April 2021

Published: 21 April 2021

Publisher's Note: MDPI stays neutral with regard to jurisdictional claims in published maps and institutional affiliations.

Copyright: (c) 2021 by the authors. Licensee MDPI, Basel, Switzerland. This article is an open access article distributed under the terms and conditions of the Creative Commons Attribution (CC BY) license (https:// creativecommons.org/licenses/by/ $4.0 /)$.

\begin{abstract}
It has been shown that monochromatic red and blue light influence photosynthesis and morphology in cucumber. It is less clear how green light impacts photosynthetic performance or morphology, either alone or in concert with other wavelengths. In this study, cucumber (Cucumis sativus) was grown under monochromatic blue, green, and red light, dichromatic blue-green, red-blue, and red-green light, as well as light containing red, green, and blue wavelengths, with or without supplemental far-red light. Photosynthetic data collected under treatment spectra at light-limiting conditions showed that both red and green light enhance photosynthesis. However, photosynthetic data collected with a $90 \%$ red, $10 \%$ blue, $1000 \mu \mathrm{mol}$ photons $\mathrm{m}^{-2} \mathrm{~s}^{-1}$, saturating light show significantly lower photosynthesis in the green, red, and red-green treatments, indicating a blue light enhancement due to photosystem stoichiometric differences. The red-green and green light treatments show improved photosynthetic capacity relative to red light, indicating partial remediation by green light. Despite a lower quantum efficiency and the lowest ambient photosynthesis levels, the monochromatic blue treatment produced among the tallest, most massive plants with the greatest leaf area and thickest stems.
\end{abstract}

Keywords: blue light; Cucumis sativus L. (cucumber); green light; light-emitting diode (LED); morphology; photosynthesis; red light; intrinsic water use efficiency (iWUE); photostationary state of phytochrome (PSS); photosynthetic photon flux density (PPFD); yield photon flux (YPF)

\section{Introduction}

While light provides energy for photosynthesis, it also directs how plants grow through the use of photoreceptors, such as phytochrome and cryptochrome, which allow the plant to respond to changes in spectral quality ranging from ultraviolet to far-red wavelengths [1]. These responses have implications for plant growth in natural conditions, from the forest floor to field conditions, as well as artificial environments such as indoor agriculture illuminated entirely by electrical lighting [2-5].

Already in the 1970s, research showed that various wavelengths of light had differing effects on photosynthesis on a quantum yield basis [6-9]. In particular, red and blue wavelengths were shown to result in greater rates of photosynthesis than green wavelengths. More recently, studies have examined chemical and structural changes to photosystem stoichiometry and function as they relate to photosynthesis $[10,11]$. It has been found that monochromatic red light results in poor growth characterized by a low photosynthetic capacity, unresponsive stomatal conductance, low specific leaf weight (leaf mass divided by leaf area), and low maximum quantum efficiency of photosystem II [10-13]. However, the addition of blue light can ameliorate these negative responses, restoring photosynthetic and physiological characteristics comparable to plants grown under white light [13]. In addition to photosynthetic responses, there is widespread interest in how spectral quality changes other aspects of physiology and development. 
One commonly reported morphological response is specific leaf weight (SLW), also called leaf mass area (LMA), which is the mass of a leaf divided by its area. This is because SLW represents an investment by the plant per unit of leaf area created, so that plants with the same plant-level net photosynthesis could have very different leaf area due to differences in SLW and different net photosynthesis rates per unit leaf area. Previous studies have found that SLW tends to increase with increasing proportion of blue light $[10,14-16]$.

Many studies have focused on the role of red, blue, and combinations of red and blue light [10,11,15,17-19]. Comparatively little research has been done on green light [20-22]. Nevertheless, it is important to include green light in spectral quality studies, as physiological responses can be the result of interactions between different wavelengths as well as other environmental variables. Green light pulses inhibited blue light-induced phototropism in dark-grown seedlings while enhancing blue light-induced phototropism in light-grown seedlings [23]. Earlier studies showed that green light reversed blue light-induced stomatal opening [24,25].

The present study used cucumber as a model plant for several reasons. First, cucumber has been documented to have high sensitivity to light quality [14-16,26,27]. Second, cucumber is one of the most produced crops under protected cultivation globally under artificial and supplemental lighting systems [28]. Third, while responses to red and blue light have been studied somewhat extensively in cucumber, to our knowledge, the response to green light and interactions between blue, green, and red light is less well understood [11,15,16,29].

Our objective was to characterize cucumber photosynthetic adaptation to diverse spectra containing combinations of red, green, and blue light to determine how light signals in complex spectra interact to influence photosynthesis. Additionally, we sought to understand how photosynthetic differences influence biomass accumulation and morphology.

\section{Results}

\subsection{Photosynthesis}

Fitting net photosynthesis (A) vs. cellular $\mathrm{CO}_{2}$ concentration $\left(\mathrm{C}_{\mathrm{c}}\right)$ curves to net photosynthesis over a range of $\mathrm{CO}_{2}$ concentrations allows for the estimation of parameters that relate to leaf-level photosynthesis and the underlying biochemistry limiting photosynthetic assimilation of $\mathrm{CO}_{2}$ (Figure 1), with estimates for the potential electron transport rate (J) and maximum RuBP carboxylation rate $\left(\mathrm{V}_{\mathrm{cmax}}\right)$ in Table $1 . \mathrm{A}_{\mathrm{c}}$ value of $\sim 270 \mathrm{ppm}$ corresponded to ambient concentrations of $\mathrm{CO}_{2}$ of $400 \mathrm{ppm}$ under measurement conditions. At that level, photosynthesis was highest in RB and GB (23.9 and $23.6 \mu \mathrm{mol} \mathrm{CO}_{2} \mathrm{~m}^{-2} \mathrm{~s}^{-1}$, respectively) followed by $\mathrm{RGB}, \mathrm{RGB}+\mathrm{FR}$, and $\mathrm{B}\left(21.0,20.5\right.$, and $19.6 \mu \mathrm{mol} \mathrm{CO} \mathrm{m}^{-2} \mathrm{~s}^{-1}$, respectively). Considerably lower photosynthesis values are found for $\mathrm{G}$ and RG (11.3 and $10.2 \mu \mathrm{mol} \mathrm{CO} \mathrm{C}^{-2} \mathrm{~s}^{-1}$, respectively) with $\mathrm{R}$ having the lowest photosynthesis of all groups at $5.8 \mu \mathrm{mol} \mathrm{CO} \mathrm{m}^{-2} \mathrm{~s}^{-1}$.

The estimated maximum rate of Rubisco carboxylation is significantly higher in $R B$ and RGB + FR than all other treatments except GB. The G, R, and RG treatments have significantly lower estimates for $V_{c m a x}$ and $J$ than treatments containing blue light-the $B$, GB, RB, RGB, and RGB + FR treatments (Table 1).

The photosynthesis measurements under $1000 \mu \mathrm{mol}$ photons $\mathrm{m}^{-2} \mathrm{~s}^{-1}$, saturating light differ substantially from the photosynthesis measurements under ambient, treatment light at $170 \mu \mathrm{mol}$ photons $\mathrm{m}^{-2} \mathrm{~s}^{-1}$ (Figure 2). Under ambient conditions, net photosynthesis was highest in RGB and RG, followed by RB and RGB + FR which had significantly higher net photosynthesis than GB or R. The B and $G$ treatments had the lowest net photosynthesis under ambient conditions. 

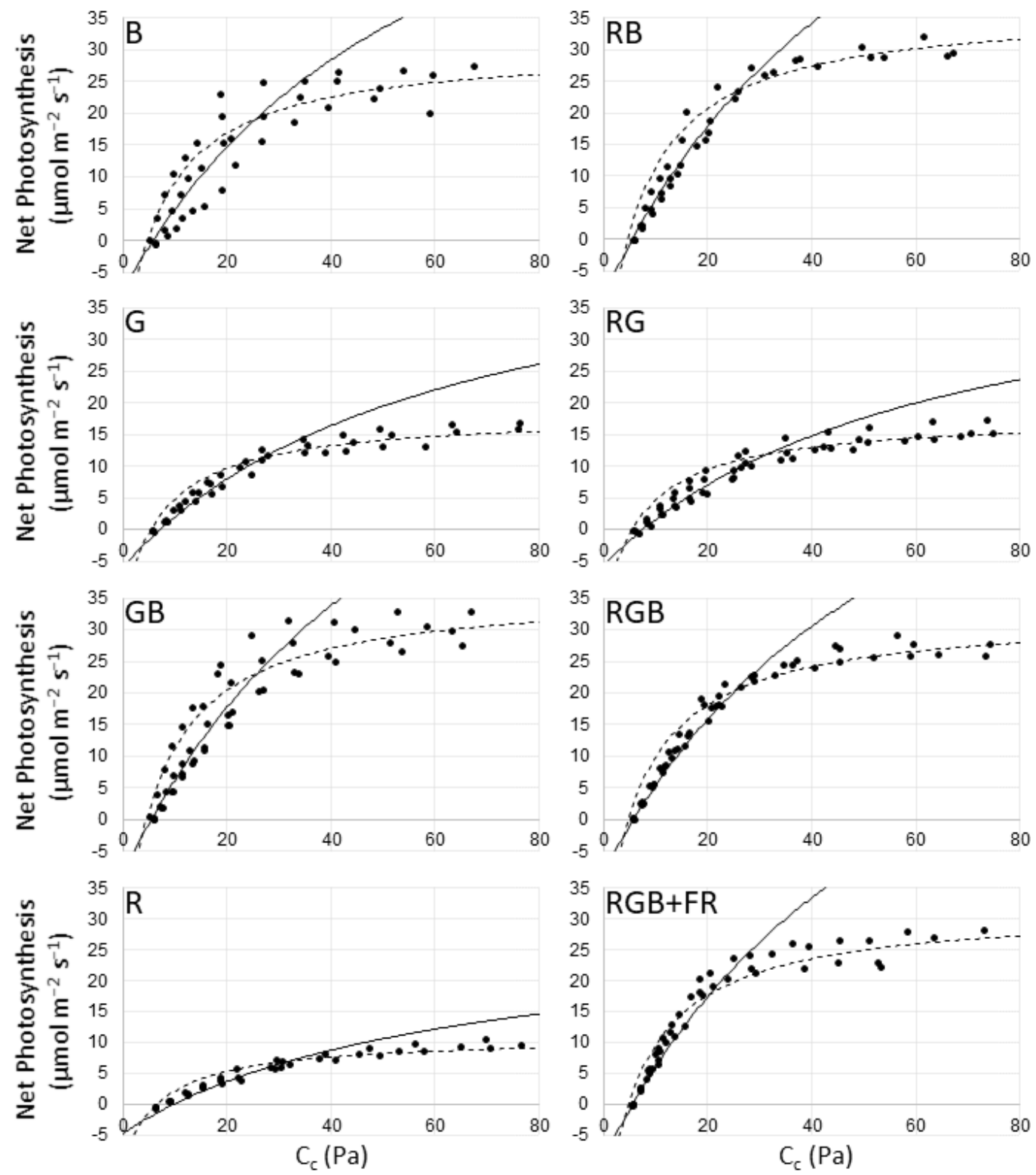

Figure 1. Net photosynthesis (A) vs. cellular $\mathrm{CO}_{2}$ concentration $\left(\mathrm{C}_{\mathrm{c}}\right)$ curve fitting for each light treatment. Filled circles represent observed net photosynthesis (A) relative to calculated Cc values. The solid line shows Rubisco limitation, while the dotted line fits RuBP limitation. Triose-phosphate utilization (TPU) limitation was not apparent.

Table 1. Maximum carboxylation rate of Rubisco (Vcmax) and potential rate of photosynthetic electron transport $(\mathrm{J})$ estimated for each light treatment. Different letters indicate significant differences $(p \leq 0.05 ; n=3$ or 4$)$.

\begin{tabular}{|c|c|c|}
\hline \multirow{2}{*}{ Treatment } & $\mathbf{J}$ & $\mathrm{V}_{\mathrm{cmax}}$ \\
\hline & $\mu \mathrm{mol} \mathrm{m} \mathrm{m}^{-2} \mathrm{~s}^{-1}$ & $\mu \mathrm{mol} \mathrm{m} \mathrm{m}^{-2} \mathrm{~s}^{-1}$ \\
\hline $\mathrm{B}$ & $132.0 \pm 5.3 c$ & $87.0 \pm 4.6 \mathrm{~b}$ \\
\hline G & $83.4 \pm 1.2 \mathrm{~d}$ & $53.6 \pm 1.2 c$ \\
\hline GB & $155.5 \pm 4.3 \mathrm{ab}$ & $102.1 \pm 3.6 \mathrm{ab}$ \\
\hline $\mathrm{R}$ & $54.3 \pm 0.7 \mathrm{e}$ & $32.2 \pm 0.8 \mathrm{~d}$ \\
\hline $\mathrm{RB}$ & $157.3 \pm 2.8 \mathrm{a}$ & $103.0 \pm 2.3 \mathrm{a}$ \\
\hline RG & $82.1 \pm 1.3 \mathrm{~d}$ & $49.0 \pm 1.2 \mathrm{c}$ \\
\hline RGB & $140.5 \pm 1.6 \mathrm{bc}$ & $93.2 \pm 1.2 b$ \\
\hline $\mathrm{RGB}+\mathrm{FR}$ & $137.7 \pm 2.7 c$ & $101.9 \pm 2.1 \mathrm{a}$ \\
\hline
\end{tabular}




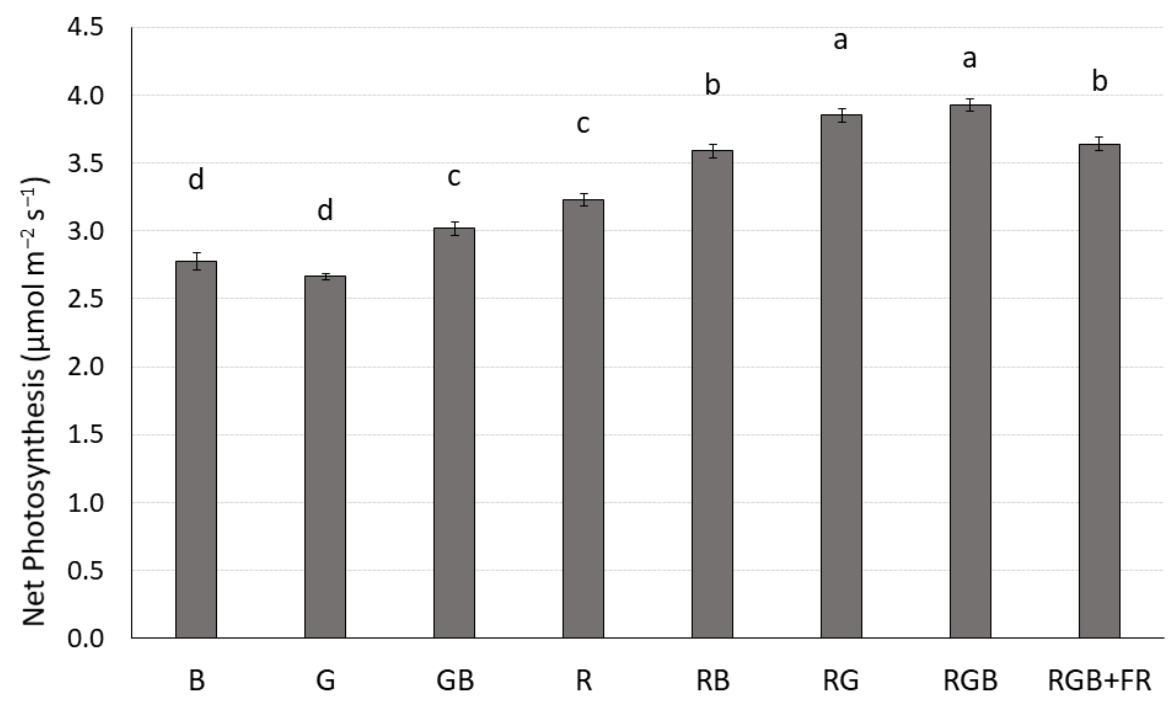

Figure 2. Net photosynthesis (A) under ambient treatment lighting. Different lowercase letters indicate significant differences $(p \leq 0.05 ; n=6)$. Error bars are the standard error. Uppercase letters indicate light treatments.

Overall, there was no correlation between net photosynthesis under ambient, treatment lighting at $170 \mu \mathrm{mol}$ photons $\mathrm{m}^{-2} \mathrm{~s}^{-1}$ and those observed at the same $\mathrm{CO}_{2}$ concentration under saturating $90 \%$ red, $10 \%$ blue light at $1000 \mu \mathrm{mol}$ photons $\mathrm{m}^{-2} \mathrm{~s}^{-1}$.

\subsection{Chlorophyll Fluorescence}

The relative operating efficiency of PSII was highest in the GB treatment and lowest in the $\mathrm{R}$ treatment (Table 2). The R and RG treatments had significantly higher $\Phi P S I I$ values than the R treatment, but significantly lower than all treatments containing blue light. The maximum quantum efficiency of PSII photochemistry $\left(\mathrm{F}_{\mathrm{v}} / \mathrm{F}_{\mathrm{m}}\right)$ was slightly under 0.83-indicating mild stress-for all treatments with no significant differences observed for any treatments (Table 2). Both light-induced and non-light-induced nonphotochemical quenching were higher in treatments lacking blue light (R, $G$, and $R G$ ) compared to treatments containing blue light (B, RB, GB, RGB, and RGB + FR).

Table 2. Maximum quantum efficiency of PSII (Fv/Fm), relative PSII operating efficiency (ФPSII), coefficient of photochemical quenching (qp), the quantum yield of non-light-induced nonphotochemical quenching ( $\Phi$ NPQ), the quantum yield of light-induced nonphotochemical quenching $(\Phi N O)$, and the fraction of oxidized plastoquinone $\left(\mathrm{q}_{\mathrm{L}}\right)$ calculated using measurements under saturating $\left(1000 \mu \mathrm{mol}\right.$ photons $\left.\mathrm{m}^{-2} \mathrm{~s}^{-1}\right) 90 \%$ red, $10 \%$ blue light. Different letters indicate significant differences $(p \leq 0.05 ; n=3$ or 4$)$.

\begin{tabular}{ccccccc}
\hline Treatment & $\boldsymbol{\Phi P S I I}$ & $\mathbf{F}_{\mathbf{v}} / \mathbf{F}_{\mathbf{m}}$ & $\boldsymbol{\Phi N P Q}$ & $\boldsymbol{\Phi N O}$ & $\mathbf{q}_{\mathbf{P}}$ & $\mathbf{q}_{\mathbf{L}}$ \\
\hline B & $0.26 \pm 0.01 \mathrm{~b}$ & $0.81 \pm 0.01 \mathrm{a}$ & $0.48 \pm 0.01 \mathrm{c}$ & $0.26 \pm 0.00 \mathrm{f}$ & $0.43 \pm 0.01 \mathrm{~b}$ & $0.23 \pm 0.01 \mathrm{ab}$ \\
G & $0.14 \pm 0.00 \mathrm{c}$ & $0.80 \pm 0.00 \mathrm{a}$ & $0.54 \pm 0.00 \mathrm{a}$ & $0.32 \pm 0.00 \mathrm{c}$ & $0.24 \pm 0.01 \mathrm{c}$ & $0.12 \pm 0.00 \mathrm{~d}$ \\
GB & $0.29 \pm 0.01 \mathrm{a}$ & $0.82 \pm 0.00 \mathrm{a}$ & $0.44 \pm 0.01 \mathrm{e}$ & $0.26 \pm 0.00 \mathrm{f}$ & $0.46 \pm 0.01 \mathrm{a}$ & $0.24 \pm 0.01 \mathrm{a}$ \\
R & $0.09 \pm 0.00 \mathrm{e}$ & $0.79 \pm 0.01 \mathrm{a}$ & $0.53 \pm 0.00 \mathrm{a}$ & $0.38 \pm 0.00 \mathrm{a}$ & $0.14 \pm 0.00 \mathrm{e}$ & $0.06 \pm 0.00 \mathrm{f}$ \\
RB & $0.26 \pm 0.01 \mathrm{~b}$ & $0.82 \pm 0.01 \mathrm{a}$ & $0.47 \pm 0.01 \mathrm{~cd}$ & $0.26 \pm 0.00 \mathrm{f}$ & $0.42 \pm 0.01 \mathrm{~b}$ & $0.22 \pm 0.01 \mathrm{bc}$ \\
RG & $0.12 \pm 0.00 \mathrm{~d}$ & $0.80 \pm 0.01 \mathrm{a}$ & $0.51 \pm 0.00 \mathrm{~b}$ & $0.37 \pm 0.00 \mathrm{~b}$ & $0.19 \pm 0.01 \mathrm{~d}$ & $0.08 \pm 0.00 \mathrm{e}$ \\
RGB & $0.27 \pm 0.01 \mathrm{~b}$ & $0.82 \pm 0.00 \mathrm{a}$ & $0.43 \pm 0.01 \mathrm{e}$ & $0.29 \pm 0.00 \mathrm{~d}$ & $0.42 \pm 0.01 \mathrm{~b}$ & $0.20 \pm 0.01 \mathrm{c}$ \\
RGB + FR & $0.27 \pm 0.01 \mathrm{~b}$ & $0.81 \pm 0.01 \mathrm{a}$ & $0.45 \pm 0.01 \mathrm{de}$ & $0.28 \pm 0.00 \mathrm{e}$ & $0.43 \pm 0.01 \mathrm{~b}$ & $0.23 \pm 0.01 \mathrm{~b}$ \\
\hline
\end{tabular}

Under light-saturating conditions, net photosynthesis was significantly lower in the G, R, and RG treatments than all other treatments (Figure 1). However, this had no apparent effect on photosynthesis under ambient conditions (Figure 2). While ambient photosynthesis was lowest in the $\mathrm{G}$ treatment, net photosynthesis in $\mathrm{R}$ was comparable 
with GB, and significantly higher than B or G. Finally, ambient photosynthesis in RG was significantly higher than all other treatments save RGB (Figure 2).

\subsection{Shoot Characteristics}

Qualitative differences between treatments can be seen in Figure 3, which shows exemplar plants (those closest to treatment average in height and mass) from the replication experiment for each treatment. Shoot dry weight showed no clear trends, except that farred light increased shoot dry weight, with an average of $2.53 \mathrm{~g}$ per plant for the RGB + FR treatment and only $1.63 \mathrm{~g}$ for the RGB treatment (Figure 4). The RGB + FR and B treatments had significantly higher dry weight than the GB, R, and RB treatments, while the RGB + FR treatment also had significantly higher dry weight than the RG and RGB treatments (Figure 4).

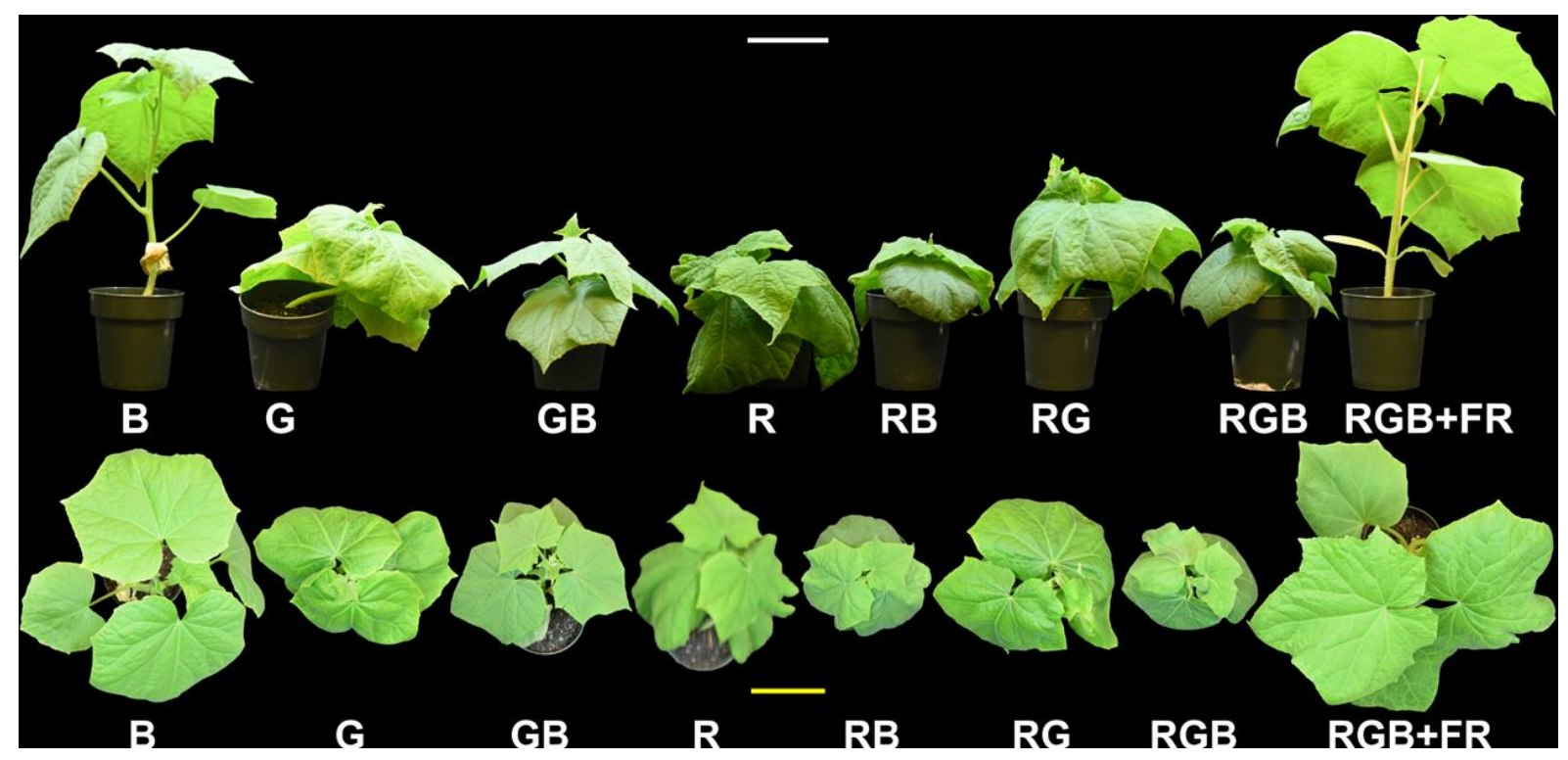

Figure 3. Profile and overhead images of representative plants, chosen by selecting the plant that was closest in dry weight and height to the treatment average. This image is a composite to allow for visual comparison between treatments. Cucumber seedlings were grown under blue (B), green (G), green-blue (GB), red (R), red-blue (RB), red-green (RG), red-green-blue (RGB), and red-green-blue with far-red (RGB + FR) light. The white bar in the upper middle is $10 \mathrm{~cm}$ for profile images, while the yellow bar in the lower middle is $10 \mathrm{~cm}$ for overhead images.

Far-red light also increased plant height, with the RGB + FR treatment being significantly taller than the RGB treatment (Figure 4). Conversely, supplemental blue light decreased plant height, with shorter plants in RB than R, GB than G, and RGB than RG. However, plants grown in the $B$ treatment were taller than all other treatments except RGB + FR. The RGB + FR and B treatments, in addition to being the tallest, also had the lowest leaf dry weight fraction (leaf dry weight divided by shoot dry weight) (Figure 4).

There were no clear trends for stem diameter, except that far-red light enhanced stem diameter, with plants in the RGB + FR treatment having significantly greater stem diameter than plants in the RGB treatment (Figure 4).

The RGB + FR treatment also resulted in significantly greater leaf area than the RGB treatment (Figure 4). Due to high within groups variability, there were no other significant trends in leaf area, although with a larger sample size, a trend of decreasing leaf area with supplemental blue light may be observed. 

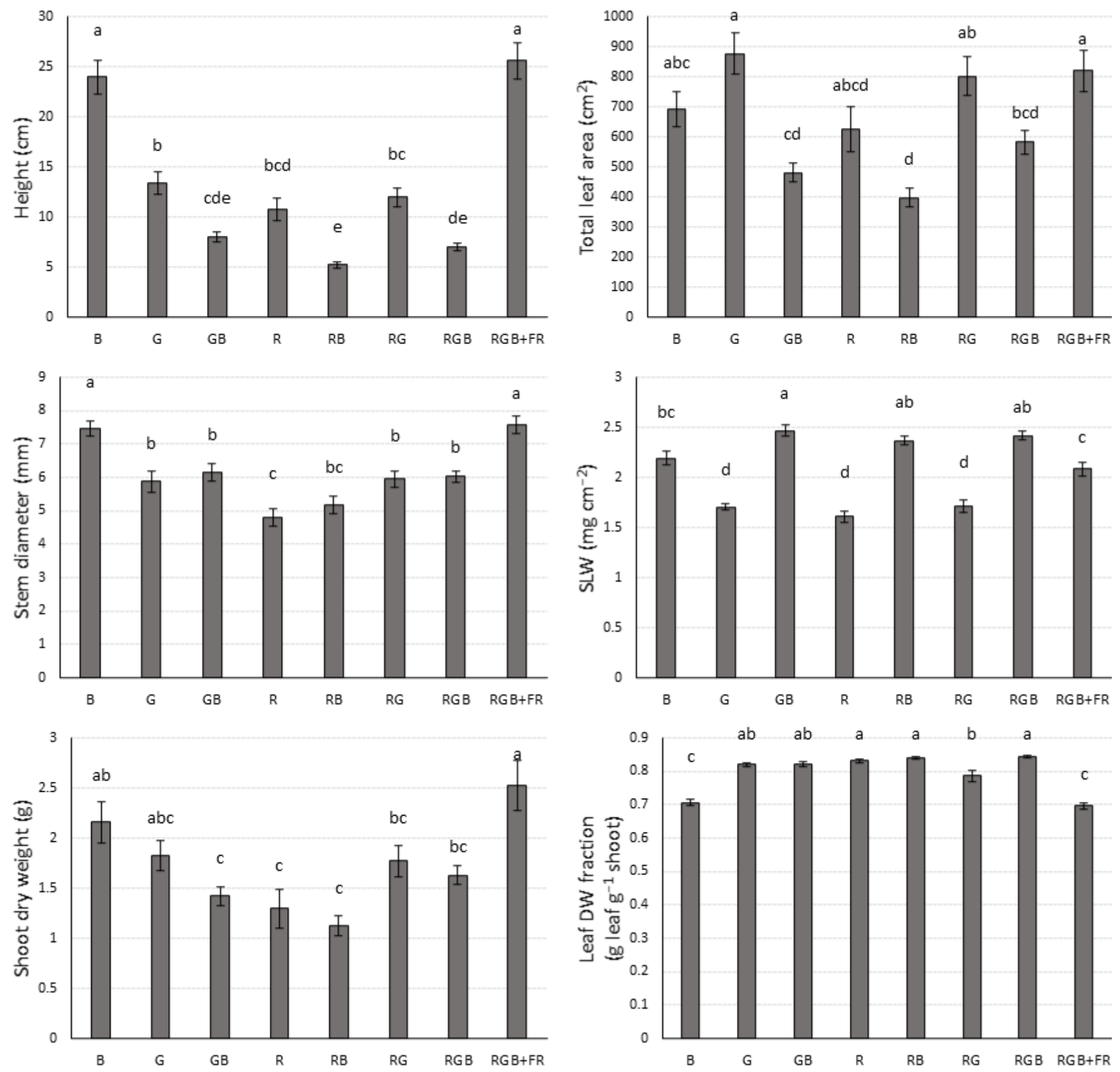

Figure 4. Shoot characteristics of cucumber under diverse spectra. Different lowercase letters indicate significant differences ( $p \leq 0.05 ; n$ is between 25 and 30 for each treatment). Uppercase letters indicate light treatments.

Specific leaf weight (SLW), the dry weight of a leaf divided by its area, does show a clear trend with blue light significantly increasing SLW. Higher specific leaf weights were observed in the GB treatment relative to $G, R B$ relative to $R$, and RGB relative to RG (Figure 4). Far-red light decreased SLW, with the RGB + FR treatment having significantly lower SLW than the RGB treatment.

\subsection{Stomatal Characteristics}

Stomatal conductance under ambient lighting was significantly higher in B $\left(0.24 \mathrm{~mol} \mathrm{~m}^{-2} \mathrm{~s}^{-1}\right)$ relative to $\mathrm{R}\left(0.09 \mathrm{~mol} \mathrm{~m}^{-2} \mathrm{~s}^{-1}\right)$ or $\mathrm{G}\left(0.09 \mathrm{~mol} \mathrm{~m}^{-2} \mathrm{~s}^{-1}\right)$ and significantly higher in GB $\left(0.28 \mathrm{~mol} \mathrm{~m}^{-2} \mathrm{~s}^{-1}\right)$ relative to $G$, in $R B\left(0.19 \mathrm{~mol} \mathrm{~m}^{-2} \mathrm{~s}^{-1}\right)$ relative to $R$, and in RGB $\left(0.27 \mathrm{~mol} \mathrm{~m}^{-2} \mathrm{~s}^{-1}\right)$ relative to RG $\left(0.09 \mathrm{~mol} \mathrm{~m}^{-2} \mathrm{~s}^{-1}\right)$, demonstrating a blue light-mediated increase in stomatal conductance (Figure 5A). 

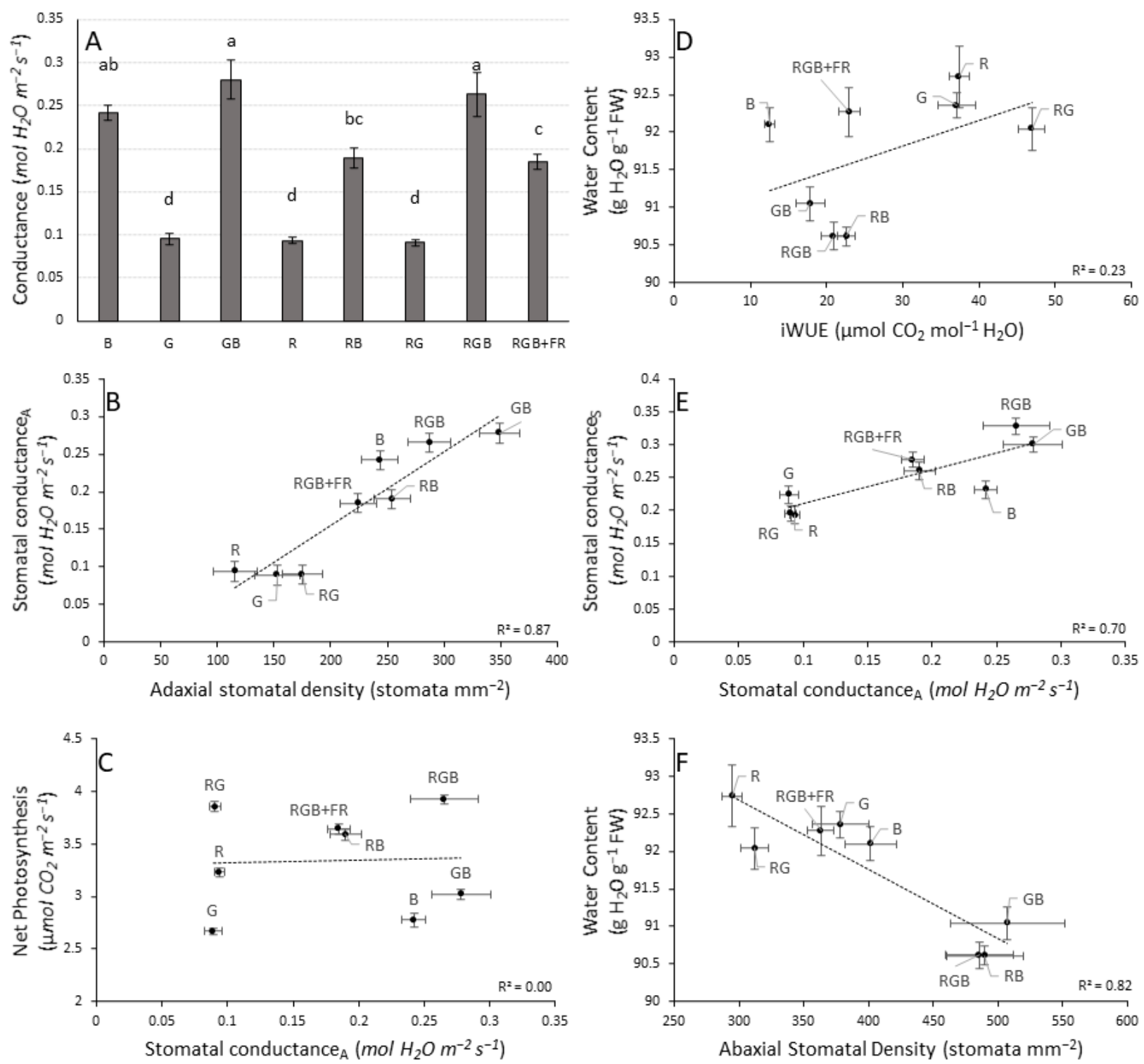

Figure 5. (A): Stomatal conductance under saturating light by light treatment. Different lowercase letters indicate significant differences ( $p \leq 0.05 ; n$ is between 25 and 30 for each treatment). (B): Stomatal conductance under ambient, treatment lighting (Stomatal conductance ${ }_{\mathrm{A}}$ ) vs. adaxial stomatal density. (C): Net photosynthesis under ambient, treatment lighting vs. stomatal conductance under ambient, treatment lighting. (D): Water content vs. instantaneous water use efficiency. (E): Stomatal conductance under saturating light vs. stomatal conductance under ambient, treatment lighting. (F): Water content vs. abaxial stomatal density. Uppercase letters indicate light treatments.

We found a significant increase in conductance from RB to RGB, but there was no difference in stomatal conductance between $G, R$, and the RG treatments (Figure 5A). Far-red light decreased stomatal conductance, with conductance significantly lower in RGB + FR $\left(0.18 \mathrm{~mol} \mathrm{~m}^{-2} \mathrm{~s}^{-1}\right)$ compared to RGB. Stomatal conductance under ambient, treatment lighting was highly correlated with adaxial stomatal density (Figure $5 B, R^{2}=0.87$ ). However, stomatal conductance was not correlated to net photosynthesis under ambient, treatment lighting (Figure $5 C, R^{2}=0.00$ ).

When measuring the A vs. $\mathrm{C}_{\mathrm{c}}$ curves, all plants were subjected to saturating levels of $90 \%$ red, $10 \%$ blue light at $1000 \mu \mathrm{mol}$ photons $\mathrm{m}^{-2} \mathrm{~s}^{-1}$. Despite being illuminated with the same spectrum, conductance trends were similar to those obtained when illuminated by treatment spectra. Overall, average conductance values under saturating light were higher in all treatments compared to ambient lighting conditions except the $\mathrm{B}$ treatment, with $R^{2}=0.70(p<0.01)$ (Figure 5E). 
Like conductance, blue light resulted in an increased stomatal density, with abaxial stomatal density higher in $B$ relative to $R$ (although not different from $G$ ), and higher abaxial density in GB relative to G, RB relative to R, and RGB relative to RG. The same trends were found for adaxial stomatal density, except that adaxial stomatal density in $\mathrm{B}$ was significantly higher than $\mathrm{G}$ (Table 3).

Table 3. Stomatal density, abaxial (AB) to adaxial (AD) stomatal density ratio, intrinsic water use efficiency, and water content of cucumber.

\begin{tabular}{cccccc}
\hline Treatment & Abaxial & Adaxial & AB:AD & iWUE & Water Content \\
\hline & Stomata $/ \mathrm{mm}^{2}$ & Stomata $/ \mathrm{mm}^{2}$ & & $\mu \mathrm{mol} \mathrm{CO}_{2} \mathrm{~mol}^{-1} \mathrm{H}_{2} \mathrm{O}$ & $\mathrm{g} \mathrm{H}_{2} \mathrm{O} 100 \mathrm{~g}^{-1} \mathrm{FW}$ \\
B & $402 \pm 22 \mathrm{bcd}$ & $243 \pm 16 \mathrm{bc}$ & $1.66 \pm 0.11 \mathrm{~b}$ & $12.5 \pm 1.4 \mathrm{~d}$ & $92.1 \pm 0.2 \mathrm{a}$ \\
$\mathrm{G}$ & $378 \pm 26 \mathrm{cde}$ & $153 \pm 20 \mathrm{de}$ & $2.67 \pm 0.13 \mathrm{a}$ & $37.1 \pm 1.5 \mathrm{~b}$ & $92.4 \pm 0.2 \mathrm{a}$ \\
$\mathrm{GB}$ & $507 \pm 25 \mathrm{a}$ & $349 \pm 18 \mathrm{a}$ & $1.55 \pm 0.12 \mathrm{~b}$ & $17.9 \pm 1.4 \mathrm{~cd}$ & $91.0 \pm 0.2 \mathrm{~b}$ \\
R & $295 \pm 25 \mathrm{e}$ & $116 \pm 19 \mathrm{e}$ & $2.76 \pm 0.13 \mathrm{a}$ & $37.4 \pm 1.4 \mathrm{~b}$ & $92.7 \pm 0.4 \mathrm{a}$ \\
RB & $490 \pm 22 \mathrm{ab}$ & $254 \pm 16 \mathrm{~b}$ & $1.99 \pm 0.11 \mathrm{~b}$ & $22.6 \pm 1.4 \mathrm{c}$ & $90.6 \pm 0.1 \mathrm{~b}$ \\
RG & $312 \pm 24 \mathrm{de}$ & $175 \pm 18 \mathrm{cde}$ & $1.82 \pm 0.12 \mathrm{~b}$ & $47.0 \pm 1.3 \mathrm{a}$ & $92.0 \pm 0.3 \mathrm{a}$ \\
RGB & $486 \pm 25 \mathrm{abc}$ & $287 \pm 19 \mathrm{ab}$ & $1.73 \pm 0.13 \mathrm{~b}$ & $20.9 \pm 1.4 \mathrm{c}$ & $90.6 \pm 0.2 \mathrm{~b}$ \\
RGB + FR & $363 \pm 21 \mathrm{de}$ & $224 \pm 16 \mathrm{bcd}$ & $1.66 \pm 0.11 \mathrm{~b}$ & $23.0 \pm 1.4 \mathrm{c}$ & $92.3 \pm 0.3 \mathrm{a}$ \\
\hline
\end{tabular}

Abaxial stomatal density was also lower in RGB + FR than RGB, though there was no difference in adaxial stomatal density (Table 3 ). We observed significantly higher abaxial:adaxial ratios for the $\mathrm{G}$ and $\mathrm{R}$ treatments relative to all other treatments.

Intrinsic water use efficiency (iWUE) under ambient conditions, which is calculated by dividing the net photosynthesis by stomatal conductance, was highest in RG, followed by $G$ and $R$, while iWUE was lowest in the B treatment. Like [30], we found no difference in iWUE between RB and RGB; however, [31] did find a significant increase in iWUE in a low R:FR treatment compared to a high R:FR treatment, while we found no difference between the RGB and RGB + FR treatment.

Intrinsic water use efficiency had only a weak correlation with water content at harvest (Figure $5 D, R^{2}=0.23$ ). Water content, the percentage of fresh weight from water, was lower in GB, RB, and RGB than all other treatments. Interestingly, while stomatal conductance was best explained by adaxial stomatal density, water content at harvest was best explained by abaxial stomatal density $\left(R^{2}=0.82\right.$, Figure $\left.5 F\right)$.

\section{Discussion}

Previous experiments found that cucumber measured under saturating light and grown under monochromatic red light showed lower photosynthesis than cucumber plants grown under red-blue light, consistent with our findings [10].

The $J$ and $V_{c \max }$ values calculated suggest that blue light significantly enhances photosynthetic capacity relative to treatments lacking blue light. Since these values are lowest in the $R$ treatment, and significantly higher in the RG and G treatments, we can also conclude that green light improves photosynthetic capacity relative to monochromatic red light. However, because the RG and $G$ treatments have significantly lower $J$ and $V_{c m a x}$ values than treatments containing blue light, the effect of green light must be lesser than that of blue light.

Previously, calculations of $\mathrm{V}_{\mathrm{cmax}}$ and $\mathrm{J}$ were found to be significantly higher in $\mathrm{B}$ than $R$; however, they found no difference in $V_{c m a x}$ between $R$ and RB, while estimates for $V_{c m a x}$ were significantly higher in RB than $R$ in our experiment [12]. Others calculated $V_{c m a x}$ for a low R:FR treatment as significantly lower than for a high R:FR treatment, while we found $V_{c m a x}$ to be significantly higher in the RGB + FR treatment compared to the RGB treatment [31].

Our findings suggest that green light enhanced net photosynthesis, since values for $\mathrm{V}_{\mathrm{cmax}}, \mathrm{J}$, and net photosynthesis were significantly greater in GB relative to $\mathrm{B}, \mathrm{RG}$ relative to R, and RGB relative to RB (Figure 3). Photosynthesis was also significantly higher in RB 
relative to $B, R G$ relative to $G$, and RGB relative to $G B$, suggesting a red light enhancement. Others have found that a broader spectrum resulted in higher fixation than a red-blue light treatment for tomato and poinsettia but saw no difference in cucumber at ambient $\mathrm{CO}_{2}$ concentrations [32]. They did observe a difference at elevated $\mathrm{CO}_{2}$, similar to the enhancement we saw for photosynthesis in RGB relative to RB at ambient $\mathrm{CO}_{2}$ and light levels. Others have found higher fixation in $B$ than $R$ for cucumber while we observed the opposite under ambient conditions $[11,12,15,33]$. During A vs. $C_{C}$ measurements, plants from the $\mathrm{B}$ treatment had a higher net photosynthesis level than plants in the $\mathrm{R}$ treatment, indicating that the choice of spectral composition, intensity, or both is critically important to comparing net photosynthesis levels between treatments, even when the same light source is used for each treatment.

It is possible that the red and green light enhancement can be described in part by the 'enhancement effect' or 'Emerson effect' which refers to the phenomenon where photosynthesis from combined spectra can be greater than the sum of its parts due to excitation energy distribution between photosystem I and photosystem II [34-36].

\subsection{Chlorophyll Fluorescence}

The maximum quantum efficiency of PSII photochemistry $\left(\mathrm{F}_{\mathrm{v}} / \mathrm{F}_{\mathrm{m}}\right)$ indicates how effectively PSII uses absorbed light energy to reduce the primary quinone acceptor of PSII $\left(\mathrm{Q}_{\mathrm{A}}\right)$ [37]. In practice, this measure can be used to assess stress in plants, as a value of $\sim 0.83$ is very consistent across species in non-stressed leaves [38]. Values below 0.83 indicate stress and a reduced maximum photosynthetic capacity; however, photosynthesis may not be reduced under ambient conditions as the quantum yield of PSII (ФPSII) is generally considerably lower than $F_{v} / F_{m}$, especially under high light intensity. A low $F_{v} / F_{m}$ is one of the symptoms of red light syndrome [11-13].

$\mathrm{F}_{\mathrm{v}} / \mathrm{F}_{\mathrm{m}}$ was qualitatively lower in $\mathrm{G}, \mathrm{R}$, and $\mathrm{RG}$ than all other treatments, indicating a reduced maximum photosynthetic efficiency with values suggesting mild stress (Table 4). These qualitative differences are supported by previous findings that a comparatively higher level of blue light in LED treatments increased $F_{v} / F_{m}$ relative to high pressure sodium treatments [39]. Others have also concluded that blue light enhances PSII photochemistry relative to red light [11-13].

PSII operating efficiency decreases with increasing light intensity, primarily due to a reduced ability to oxidize $Q_{A}$ rather than an increase in non-photochemical quenching (NPQ) $[37,40]$. Therefore, it is not surprising that under saturating light the PSII operating efficiencies observed were much lower than $\mathrm{F}_{\mathrm{v}} / \mathrm{F}_{\mathrm{m}}$. PSII operating efficiency was significantly lower in G, R, and RG than all other treatments (with $\Phi P S I I$ in R significantly lower than RG, which was significantly lower than ФPSII in G) (Table 2). It is not possible to estimate electron transport rate or the quantum yield of $\mathrm{CO}_{2}$, since we cannot account for alternative electron sinks to PSII because these measurements were taken under atmospheric $\mathrm{O}_{2}$ concentrations. Nevertheless, $\Phi$ PSII gives an estimate on the upper limit of possible photosynthetic carbon assimilation under a given condition, and the trend observed is very similar to the trend in net photosynthesis observed.

Despite the lower $\Phi P S I I$ values, $\Phi N P Q$, the quantum yield of light-induced quenching, and $\Phi N O$, non-light-induced quenching, are both significantly higher in the $G, R$, and RG treatments than all other treatments (Table 2). Together, these data suggest that electron acceptors downstream of PSII are insufficient in the G, R, and RG treatments compared to the other treatments, and that $G, R$, and $R G$ treatments are compensating by increasing nonphotochemical quenching to reduce photo-induced damage. Since the spectral quality and intensity used to excite the photosystems were identical across treatments during light-saturated measurements, one would expect differences in net photosynthesis and chlorophyll fluorescence to be related to adaptive differences between light treatments. 
Table 4. Color breakdown for light treatment spectra as a percentage of total photosynthetic photon flux density (PPFD). Wavelength ranges for the traditional method indicate the typically defined range for each color, while the wavelength range for the bar method indicates the range in which $>99 \%$ of the light is emitted from a given bar color.

\begin{tabular}{|c|c|c|c|c|}
\hline \multirow{9}{*}{$\begin{array}{l}\text { Traditional } \\
\text { method }\end{array}$} & Treatment & $\begin{array}{c}\text { Red } \\
(600-700 \mathrm{~nm})\end{array}$ & $\begin{array}{c}\text { Green } \\
(500-600 \mathrm{~nm})\end{array}$ & $\begin{array}{c}\text { Blue } \\
(400-500 \mathrm{~nm})\end{array}$ \\
\hline & B & 0 & 1 & 99 \\
\hline & $\mathrm{G}$ & 0 & 93 & 6 \\
\hline & GB & 0 & 37 & 63 \\
\hline & $\mathrm{R}$ & 100 & 0 & 0 \\
\hline & $\mathrm{RB}$ & 47 & 1 & 52 \\
\hline & RG & 65 & 31 & 3 \\
\hline & RGB & 38 & 22 & 40 \\
\hline & RGB + FR & 40 & 20 & 40 \\
\hline \multirow{9}{*}{$\begin{array}{l}\text { Bar } \\
\text { method }\end{array}$} & Treatment & $\begin{array}{c}\text { Red } \\
(623-684 \mathrm{~nm})\end{array}$ & $\begin{array}{c}\text { Green } \\
(486-582 \mathrm{~nm})\end{array}$ & $\begin{array}{c}\text { Blue } \\
(432-500 \mathrm{~nm})\end{array}$ \\
\hline & B & 0 & 0 & 100 \\
\hline & $\mathrm{G}$ & 0 & 100 & 0 \\
\hline & GB & 0 & 38 & 62 \\
\hline & $\mathrm{R}$ & 100 & 0 & 0 \\
\hline & $\mathrm{RB}$ & 47 & 0 & 53 \\
\hline & $\mathrm{RG}$ & 65 & 35 & 0 \\
\hline & RGB & 38 & 23 & 39 \\
\hline & RGB + FR & 40 & 21 & 39 \\
\hline
\end{tabular}

Plants have a variety of mechanisms to respond to changes in light quality. In the short term, light-harvesting complex II (LHC-II) can be transferred from PSII to PSI to help balance excitation energy between the two systems to improve electron transport efficiency [41]. In the long term, algae, cyanobacteria, and higher plants adjust the stoichiometry of photosystem I (PSI) and photosystem II (PSII) in response to light quality to improve photosynthetic efficiency [42-45] as well as their pigment composition [42,46] to more efficiently absorb ambient light.

PSII is primarily excited by wavelengths at $\sim 450-640 \mathrm{~nm}$ while PSI uses light above $680 \mathrm{~nm}$ much more efficiently than PSII [47]. Since the blue LEDs are the only source of photons at $450 \mathrm{~nm}$ in our light treatments, treatments lacking these wavelengths $(G, R$, and RG) likely have adjusted stoichiometry to decrease the number of PSI complexes relative to PSII to improve electron transport efficiency due to less efficient excitation of PSII relative to PSI. As the green LEDs supply light within the range that PSII can use effectively, this stoichiometric adjustment would be expected to be most pronounced in the R treatment, and less so in the $G$ and RG treatments.

When the plants were exposed to the novel light treatment (90\% red, 10\% blue) during A vs. $C_{C}$ measurements they could use transient LHC-II to improve the balance of excitation between PSI and PSII, but the capacity to balance in the G, R, and RG treatments may have been limited by extreme stoichiometric differences not seen in the other treatments. This would explain the much poorer performance of these three treatments relative to the other treatments and the poorer performance of $R$ relative to $G$ and RG during A vs. $C_{c}$ measurements, while the same long-term adaptations may have allowed for the trends seen in Figure 1 during measurement under ambient lighting.

In any case, neither the photosynthesis measurements under saturating $90 \%$ red, $10 \%$ blue light at $1000 \mu \mathrm{mol}$ photons $\mathrm{m}^{-2} \mathrm{~s}^{-1}$ nor ambient light at $170 \mu \mathrm{mol}$ photons $\mathrm{m}^{-2} \mathrm{~s}^{-1}$ correlate well with shoot dry weight. There are many potential reasons for the lack of correlation between shoot biomass and photosynthesis measurements. First, the dry weight data include only shoot biomass, not root biomass. It is possible that with root biomass, the whole-plant biomass values would correlate well with the net photosynthesis measurements observed. The photosynthesis values presented are on a per-area basis. Leaf area and specific leaf weight (leaf area divided by leaf dry weight) vary between treatments. 
It is therefore possible that plants with equivalent net photosynthesis rates could have very different whole plant growth rates due to differences in leaf area [48].

\subsection{Stomatal Conductance}

Others have also noted a trend of increasing stomatal conductance in cucumber with increasing blue light $[11,15]$. Significantly higher stomatal conductance in cucumber grown under monochromatic blue light compared to cucumber grown under monochromatic red light was found here and previously [33]. Another study also measured significantly higher stomatal conductance in cucumber seedlings under a monochromatic blue light treatment relative to a monochromatic red light treatment and found no difference between the B treatment and RB treatment, which our results support [12]. However, we found conductance in RB to be significantly greater compared to $R$, while they found no difference in conductance between the R and RB treatment. Our results differ from a finding that there was no difference in stomatal conductance of cucumber between a white light LED treatment and a red-blue light treatment, while we found conductance to be significantly higher in RGB compared to RB [30]. It is possible that this is because our RGB treatment was roughly 2:1:2 B:G:R light while the white light treatment in their experiment was roughly 1:2:1 B:G:R light. In Arabidopsis, red-blue light increased stomatal aperture more than red light alone, while red-green-blue light showed no increase in aperture relative to red light alone [24].

Our findings on blue and green light effects on stomatal conductance are similar to those findings in Arabidopsis, as they observed no difference in aperture between $\mathrm{R}$ and RG. However, they found a significant decrease in stomatal aperture for monochromatic G compared to R or RG while we found no difference. It is possible that this is because our plants had time to form long-term adaptations to light quality, while the Arabidopsis leaves were being exposed to a novel lighting condition and therefore only had shortterm responses.

Another study found that a decreased ratio of R:FR resulted in a decrease in stomatal conductance in cucumber relative to a treatment with high R:FR light [31]. This is similar to our findings between the RGB and RGB + FR treatments, where RGB + FR had significantly lower conductance than the RGB treatment.

The fact that similar conductance trends were observed despite illumination under very different spectral quality suggests that the results are driven more by physical differences in the leaves than transient chemical expression induced by light signaling.

This is supported by the stomatal density data shown in Table 3 and the correlation between stomatal conductance under ambient lighting and adaxial stomatal density (Figure 5).

The stomatal density trends we observed agree with previous findings of significantly higher average stomatal density in B and RB light treatments relative to R [29]. Others found that a decreased R:FR ratio resulted in a decreased stomatal density, although they found a significant decrease in adaxial rather than abaxial stomatal density [31]. They also found a significant difference in the abaxial to adaxial stomatal ratio (AB:AD) while we found no difference between RGB and RGB + FR.

Stomatal density also explains more than half of the variation found in intrinsic water use efficiency (iWUE) under ambient conditions, which is calculated by dividing the net photosynthesis by stomatal conductance $\left(R^{2}=0.58\right.$, Figure 5$)$.

\subsection{Morphology}

In red-blue light treatments, increasing proportions of blue light led to reduced leaf area [15]. Previously, it was found that monochromatic blue light resulted in the highest leaf area, followed by white light, which had significantly higher leaf area than monochromatic red light [33]. We did not find any statistically significant differences between these treatments, but that may be due to the high within-group variation and relatively low sample size, as the mean leaf areas in our treatments follow the same trend. 
The same study found no difference between R, B, and RB treatments, while we found RB to have significantly lower leaf area than R or B [33]. The effect of decreasing the R:FR ratio on leaf area is species specific, with some showing decreased leaf area, while others like petunia show an increase in leaf area [49]. In our experiment, far-red light mediated increased leaf area, which has been found by others [50].

Cucumber grown under monochromatic red light was taller than cucumber grown under a 1:1 ratio of red to blue, with both treatments being shorter than a monochromatic blue treatment, which is consistent with our findings [15]. Far-red-regulated increases in plant height are well documented [50-53]. As the height of the light fixtures was not adjusted during the experiment, it is possible that plants which grew taller received more irradiation than shorter plants, potentially affecting total shoot biomass.

The leaf area and specific leaf weights observed may also help to explain the average shoot biomass for each treatment. For example, the $G$ treatment had the lowest net photosynthesis per unit leaf area along with the B treatment (Figure 2). However, both the $G$ and $B$ treatments had high leaf area, potentially allowing for the same or greater total photosynthesis as a treatment with lower leaf area but higher net photosynthesis per unit area, such as the RB treatment which had higher net photosynthesis per unit area, but lower leaf area and shoot dry weight.

In the case of the G treatment, a low SLW meant that more leaf area could be produced using the same amount of photosynthate compared to the RB treatment. The SLWs for the $B$ and RB treatments were not significantly different, but the B treatment plants were much taller, potentially resulting in higher average light intensity for the duration of the experiment.

\section{Materials and Methods}

The experimental work consisted of 2 replications over time. Cucumber (Cucumis sativus cv. Diva) seeds were germinated in total darkness at $32{ }^{\circ} \mathrm{C}$. Once germinated, seeds were transplanted into $4 \mathrm{in}$. pots containing UC mix $(1 / 3$ peat moss, $1 / 3 \mathrm{redwood}$ sawdust, $1 / 3$ fine sand), covered with an additional $100 \mathrm{~cm}^{3}$ of UC mix, and randomly distributed into their light treatment chambers. Plants were irrigated with $\frac{1}{2}$ strength Hoagland's solution every third day for the first two weeks, then daily thereafter [54]. Leaf photosynthetic rate, stomatal conductance, and fluorescence measurements were obtained during both replications. Morphological measurements were made four weeks after transplant.

In both replications, plants were grown in chambers $61 \mathrm{~cm}$ wide, $122 \mathrm{~cm}$ long, and $90 \mathrm{~cm}$ tall. An 8 in. duct fan exhausted air from the chambers so that the average temperature was $23.0 \pm 0.2{ }^{\circ} \mathrm{C}$ when the lights were on and $20.9 \pm 0.2{ }^{\circ} \mathrm{C}$ when the lights were off.

Each chamber was illuminated with lamps consisting of various light-emitting diode (LED) bars (Demegrow, Inc., Sacramento, CA, USA) specifically designed to provide a custom spectrum in each chamber. Fixtures consisted of different combinations of diodes emitting far-red, red, green, or blue light, with peak intensities at wavelengths of $744 \mathrm{~nm}$, $661 \mathrm{~nm}, 521 \mathrm{~nm}$, and $460 \mathrm{~nm}$, respectively. Spectra of the resulting lamp systems were measured with a JAZ spectrometer (model: JAZ spectrometer, Ocean Optics, Largo, FL, USA). The full width at half maximum for each peak was 21.8, 20.7, 33.6, and $21.6 \mathrm{~nm}$ for far-red, red, green, and blue peaks, respectively (Figure 6). Green light in the RGB and RGB + FR treatments came from 15,000 K white LEDs, which is why the green peak is broader in these treatments than other treatments containing green light. Each fixture installation was configured so that all had comparable photosynthetic photon flux density (PPFD) levels of $120 \mu \mathrm{mol}$ photons $\mathrm{m}^{-2} \mathrm{~s}^{-1}$ in each chamber. This was achieved by raising or lowering the lamp array in each chamber and averaging measurements over a 45-point grid. 

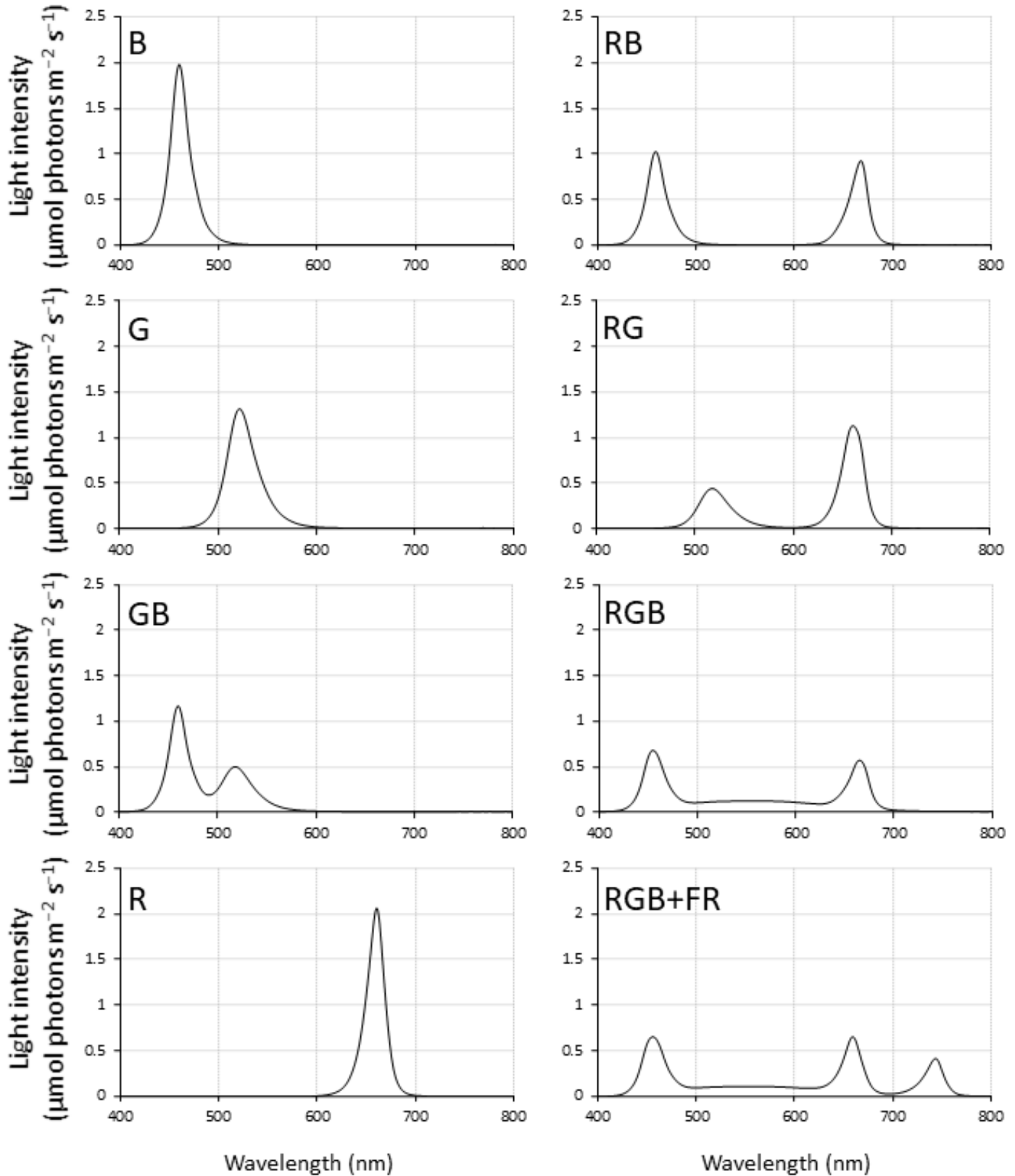

Figure 6. Light treatment spectra: monochromatic blue (B), monochromatic green (G), monochromatic red (R), green-blue $(\mathrm{GB})$, red-blue (RB), red-green (RG), red-green-blue (RGB), and red-green-blue with far red (RGB + FR).

Where both colors were present, the intensity of blue and red are roughly $1: 1$, blue and green are 2:1, and red and green are 2:1; actual percentages of total light as in Table 4 . Since the energy of far-red light does not contribute to photosynthetic photon flux density (PPFD), the RGB and RGB + FR treatments have roughly the same PPFD and light ratios between 400 and $700 \mathrm{~nm}$, but $18 \%$ of all incident irradiation between 400 to $800 \mathrm{~nm}$ in the RGB + FR treatment was in the far-red $(700$ to $800 \mathrm{~nm})$ region. One percent of incident photons were in the far-red region in the RGB treatment, while all other treatments had negligible levels of far-red light. In addition to the traditional color quantification (red $600-700 \mathrm{~nm}$, green $500-600 \mathrm{~nm}$, and blue $400-500 \mathrm{~nm}$ ), the light is reported based on the quantity from each 'color' of LED bar. This was determined by only powering LED bars of a given light color and measuring PPFD, then calculating the percentage of total PPFD from that bar color (Table 4).

Yield photon flux (YPF) was calculated for each light treatment according to [9] by multiplying relative quantum efficiency at a given wavelength with the photon flux at 
that wavelength, then integrating from 300 to $800 \mathrm{~nm}$ (Table 5). The YPF model adjusts PPFD based on the likelihood that a photon of a given wavelength will be absorbed and the likelihood that the energy will be used for photosynthesis once absorbed.

Table 5. Yield photon flux (YPF) and photostationary state of phytochrome (PSS) for each light treatment.

\begin{tabular}{ccc}
\hline \multirow{2}{*}{ Treatment } & YPF & PSS \\
\cline { 2 - 3 } & $\boldsymbol{\mu m o l ~ m}^{-\mathbf{2}} \mathbf{~ s}^{-\mathbf{1}}: \mathbf{P}_{\text {total }}$ \\
\hline B & 88 & 0.51 \\
G & 94 & 0.83 \\
GB & 90 & 0.62 \\
R & 114 & 0.89 \\
RB & 98 & 0.86 \\
RG & 106 & 0.88 \\
RGB & 102 & 0.86 \\
RGB + FR & 104 & 0.76 \\
\hline
\end{tabular}

Finally, photostationary state of phytochrome (PSS), an estimate of active phytochrome as a portion of total phytochrome, was calculated using

$$
P S S=\left(\sum_{300}^{800} N_{\lambda} \sigma_{r_{\lambda}}\right) /\left(\sum_{300}^{800} N_{\lambda} \sigma_{r_{\lambda}}+\sum_{300}^{800} N_{\lambda} \sigma_{f r_{\lambda}}\right)
$$

as reported in Table 2 [9].

Equation (1) gives PSS where $N$ is incident photon flux at a given wavelength $(\lambda), \sigma_{r}$ is the photochemical cross section of $\mathrm{P}_{\mathrm{r}}$ (the red-absorbing, inactive form of phytochrome) at $\lambda$, and $\sigma_{f r}$ is the photochemical cross section of $\mathrm{P}_{\mathrm{fr}}$ (the far-red-absorbing, active form of phytochrome) at $\lambda$.

Photosynthesis was measured in two ways. First, using a LI-6400 with a clear-top chamber (LI-COR Biosciences, Lincoln, NE, USA), net photosynthesis (A) and stomatal conductance $\left(g_{s}\right)$ were measured at an ambient $\mathrm{CO}_{2}$ concentration $\left(C_{a}\right)$ of 400 ppm and a leaf temperature of $25{ }^{\circ} \mathrm{C}$, illuminated by treatment light spectra at ambient intensity.

Second, $A$ vs. $C_{c}$ response curves, the net photosynthesis rate obtained under varying concentrations of $\mathrm{CO}_{2}$ in the chloroplast $\left(\mathrm{C}_{\mathrm{c}}\right)$ under saturating light, were measured using the LI-6400 portable photosynthesis system with a 6400-40 leaf chamber fluorometer attachment (LI-COR Biosciences, Lincoln, NE, USA) in order to gain insight about possible molecular adaptations to the light environment. Measurements were taken at external $\mathrm{CO}_{2}$ concentrations of $400,300,250,200,150,100,50,400,500,600,850$, and 1000 ppm in that order. Following initial fluorescence measurements, the plants had half an hour to adapt to light at $1000 \mu \mathrm{mol} \mathrm{m} \mathrm{m}^{-2} \mathrm{~s}^{-1}$. Each $\mathrm{CO}_{2}$ concentration was held for two to four minutes at a flowrate of $300 \mu \mathrm{mol} \mathrm{s}{ }^{-1}$ with leaf temperature set to $25^{\circ} \mathrm{C}$ while the plant was at room temperature $\left(23\right.$ to $\left.26^{\circ} \mathrm{C}\right)$. The first true leaf, unshaded by neighboring leaves, was measured.

Plants were first dark adapted for half an hour before initial measurements. Fluorescence measurements were taken on the dark-adapted leaves, before acclimating to the light for a half hour. The minimum chlorophyll fluorescence for dark-adapted leaves $\left(\mathrm{F}_{\mathrm{o}}\right)$, maximum light- and dark-adapted chlorophyll fluorescence ( $\mathrm{F}_{\mathrm{m}}$ ' and $\mathrm{F}_{\mathrm{m}}$, respectively), and steady state light-adapted chlorophyll fluorescence $\left(\mathrm{F}^{\prime}\right)$ were measured. The maximum quantum efficiency of PSII $\left(\mathrm{F}_{\mathrm{v}} / \mathrm{F}_{\mathrm{m}}\right)$, the relative PSII operating efficiency (ФPSII), the coefficient of photochemical quenching $\left(q_{p}\right)$, the quantum yield of non-light-induced nonphotochemical quenching $(\Phi \mathrm{NPQ})$, and the quantum yield of light-induced nonphotochemical quenching $(\Phi N O)$ were calculated according to [37]. The fraction of oxidized plastoquinone, $\mathrm{q}_{\mathrm{L}}$, was calculated according to [55]. Due to the difficulties of measuring $\mathrm{F}_{\mathrm{O}}{ }^{\prime}$, the minimal fluorescence of a light-adapted leaf, it was calculated using the equation $\mathrm{F}_{\mathrm{o}}{ }^{\prime}=\mathrm{F}_{\mathrm{o}} /\left[\left(\mathrm{F}_{\mathrm{v}} / \mathrm{F}_{\mathrm{m}}\right)+\left(\mathrm{F}_{\mathrm{o}} / \mathrm{F}_{\mathrm{m}}{ }^{\prime}\right)\right]$ where $\mathrm{F}_{\mathrm{o}}$ is the minimal fluorescence of a dark-adapted leaf, 
$\mathrm{F}_{\mathrm{m}}$ is the maximal fluorescence from a dark-adapted leaf, $\mathrm{F}_{\mathrm{m}}$ ' is the maximal fluorescence from a light-adapted leaf, and $F_{v}$ is the difference between $F_{m}$ and $F_{o}$ [40].

A vs. $C_{c}$ curve fitting was done using SAS Studio 3.8 software via the NLIN procedure, a procedure for fitting nonlinear models, using Equations (2)-(4) [56,57]. Typically, these model fittings involve 3 segments representing photosynthesis as limited either by the maximum ribulose-1,5-bisphosphate (RuBP) carboxylation rate Equation (2), the RuBP regeneration rate Equation (3), or the triose phosphate utilization (TPU) rate. However, our data suggest that TPU was not a limiting factor and so we fitted to only the Rubisco-limiting (Equation (2)) and the RuBP-limiting curves (Equation (3)). The equation for calculating the concentration of $\mathrm{CO}_{2}$ at Rubisco, $\mathrm{C}_{\mathrm{c}}$, has also been included (Equation (4)).

$$
\begin{gathered}
A=V_{c m a x}\left[\frac{C_{c}-\Gamma^{*}}{C_{c}+K_{c}\left(1+\frac{O}{K_{o}}\right)}\right]-R_{d} \\
A=J\left[\frac{C_{c}-\Gamma^{*}}{4 C_{c}+8 \Gamma^{*}}\right]-R_{d} \\
C_{c}=C_{i}-\frac{A}{g_{m} P_{a t m}}
\end{gathered}
$$

where $C_{i}$ is the intercellular concentration of $\mathrm{CO}_{2}, \mathrm{C}_{c}$ is the concentration of $\mathrm{CO}_{2}$ at Rubisco, $A$ is net $\mathrm{CO}_{2}$ assimilation, $V_{c \max }$ is maximum carboxylation rate of Rubisco, $\Gamma^{*}$ is the point at which oxygenation is twice the rate of carboxylation $\left(\mathrm{CO}_{2}\right.$ uptake equals $\mathrm{CO}_{2}$ photorespiratory release), $K_{o}$ is the inhibition constant of Rubisco for oxygen, $K_{c}$ is the Michaelis-Menten constant of Rubisco for $\mathrm{CO}_{2}, \mathrm{O}$ is the partial pressure of $\mathrm{O}_{2}$ at $\mathrm{Ru}$ bisco, $R_{d}$ is non-photorespiratory $\mathrm{CO}_{2}$ release, $J$ is the rate of electron transport, $P_{a t m}$ is atmospheric pressure, and $g_{m}$ is mesophyll conductance.

Due to the difficulty of accurately determining $\mathrm{g}_{\mathrm{m}}$ due to the method of data collection and initial fittings determining that $\mathrm{g}_{\mathrm{m}}$ did not significantly differ between any treatments, the overall average value of $2.12 \mu \mathrm{mol} \mathrm{m}^{-2} \mathrm{~s}^{-1} \mathrm{~Pa}^{-1}$ was used [58]. Likewise, since estimates of $R_{d}$ did not significantly differ between treatments, an average value of $2.71 \mu \mathrm{mol}$ $\mathrm{CO}_{2} \mathrm{~m}^{-2} \mathrm{~s}^{-1}$ was used.

All plants' shoots were severed at the substrate surface and weighed for fresh weight, separated into leaf blades and all other material (stem, petioles, cotyledons, and leaves $<2 \mathrm{~cm}^{2}$ ), oven dried for $72 \mathrm{~h}$ at $60^{\circ} \mathrm{C}$, and weighed to obtain dry weights. Stem diameter was measured with an electronic caliper just below the cotyledons with the caliper arm held parallel to the cotyledons to give a consistent measurement for seedlings with non-circular stem cross-sections. Stem height was measured from the point at which the shoot was severed to the base of the apical meristem to the nearest millimeter. The two largest leaves on each plant had length, width, petiole length, and leaf blade area measured. Additionally, total leaf area was measured using a LI-COR 3100 leaf area meter (LI-COR Biosciences, Lincoln, NE, USA). Finally, stomatal density was measured by taking a $1 \mathrm{~cm}$ by $2 \mathrm{~cm}$ section of leaf tissue adjacent to the midrib approximately halfway between leaf tip and leaf blade base and applying clear nail polish [59].

All means separations were determined using SAS Studio software 3.8 (SAS Institute Inc., Cary, NC, USA). Data from the two replications were treated as separate blocks with means separation analyzed by a Tukey-Kramer HSD $(p=0.05)$.

\section{Conclusions}

Plants adapt to light signals by adjusting photosystem stoichiometry. In monochromatic red light, this reduces photosynthetic capacity of the plant under broad spectra and saturating light conditions. However, this stoichiometric imbalance is not seen in spectra containing blue light and is partially remediated by spectra containing green light. Despite this observance under saturating light conditions, monochromatic green light had lower net photosynthesis rates than monochromatic red light under ambient conditions. Never- 
theless, other factors, such as morphological adaptations like height, leaf area, and SLW seem to drive biomass accumulation as much or more than net photosynthesis per unit leaf area, given that plants grown under monochromatic blue light were tied for lowest ambient net photosynthetic rate with monochromatic green light, but the $\mathrm{B}$ treatment produced more massive plants than the GB, R, and RB treatments which all had higher net photosynthesis under ambient conditions than the $\mathrm{B}$ treatment plants.

Author Contributions: Conceptualization, N.B.C.; methodology, N.B.C.; validation, N.B.C.; formal analysis, N.B.C.; investigation, N.B.C.; resources, J.H.L.; data curation, N.B.C.; writing—original draft preparation, N.B.C.; writing—review and editing, N.B.C. and J.H.L.; visualization, N.B.C.; supervision, N.B.C.; project administration, N.B.C.; funding acquisition, J.H.L. All authors have read and agreed to the published version of the manuscript.

Funding: Undergraduate interns were funded by The Robert and Lien Chen Family Foundation.

Institutional Review Board Statement: Not applicable.

Informed Consent Statement: Not applicable.

Data Availability Statement: Data are available upon request.

Acknowledgments: We would like to thank student assistants Hannah Vahldick, Howard Tan, and Hala Alsaid for their help setting up the experiment and collecting data, and Sophia Belvoir, Makenzie Salyer, Jorge Rodriguez, and Shaokun Meng for their help collecting data.

Conflicts of Interest: The authors declare no conflict of interest. The funders had no role in the design of the study; in the collection, analyses, or interpretation of data; in the writing of the manuscript, or in the decision to publish the results.

\section{References}

1. Huché-Thélier, L.; Crespel, L.; Le Gourrierec, J.; Morel, P.; Sakr, S.; Leduc, N. Light signaling and plant responses to blue and UV radiations-Perspectives for applications in horticulture. Environ. Exp. Bot. 2016, 121, 22-38. [CrossRef]

2. Sellaro, R.; Crepy, M.; Trupkin, S.A.; Karayekov, E.; Buckovsky, A.S.; Rossi, C.; Casal, J.J. Cryptochrome as a Sensor of the Blue/Green Ratio of Natural Radiation in Arabidopsis. Plant Physiol. 2010, 154, 401-409. [CrossRef] [PubMed]

3. Kasperbauer, M.J. Far-red light reflection from green leaves and effects on phytochrome-mediated assimilate partitioning under field conditions. Plant Physiol. 1987, 85, 350-354. [CrossRef] [PubMed]

4. Ballaré, C.L. Light regulation of plant defense. Annu. Rev. Plant Biol. 2014, 65, 335-363. [CrossRef] [PubMed]

5. Massa, G.; Graham, T.; Haire, T.; Flemming II, C.; Gerard, N.; Wheeler, R. Light-emitting diode light transmission through leaf tissue of seven different crops. HortScience 2015, 50, 501-506. [CrossRef]

6. McCree, K.J. The action spectrum, absorptance and quantum yield of photosynthesis in crop plants. Agric. Meteorol. 1972, 9, 191-216. [CrossRef]

7. Inada, K. Action spectra for photosynthesis in higher plants. Plant Cell Physiol. 1976, 17, 355-365.

8. Evans, J.R. The dependence of quantum yield on wavelength and growth irradiance. Aust. J. Plant Physiol. 1987, 14, 69-79. [CrossRef]

9. Sager, J.C.; Smith, W.O.; Edwards, J.L.; Cyr, K.L. Photosynthetic efficiency and phytochrome photoequilibria determination using spectral data. ASABE 1988, 31, 1882-1889. [CrossRef]

10. Trouwborst, G.; Hogewoning, S.W.; van Kooten, O.; Harbinson, J.; van Ieperen, W. Plasticity of photosynthesis after the 'red light syndrome' in cucumber. Environ. Exp. Bot. 2016, 121, 75-82. [CrossRef]

11. Hogewoning, S.W.; Trouwborst, G.; Maljaars, H.; Poorter, H.; van Ieperen, W.; Harbinson, J. Blue light dose-response of leaf photosynthesis, morphology, and chemical composition of Cucumis sativus grown under different combinations of red and blue light. J. Exp. Bot. 2010, 61, 3107-3117. [CrossRef]

12. Miao, Y.; Wang, X.; Gao, L.; Chen, Q.; Mei, Q. Blue light is more essential than red light for maintaining the activities of photosystem II and I and photosynthetic electron transport capacity in cucumber leaves. J. Integr. Agric. 2016, 15, 87-100. [CrossRef]

13. Miao, Y.; Chen, Q.; Qu, M.; Gao, L.; Hou, L. Blue light alleviates 'red light syndrome' by regulating chloroplast ultrastructure, photosynthetic traits and nutrient accumulation in cucumber plants. Sci. Hortic. 2019, 257, 108680. [CrossRef]

14. Trouwborst, G.; Oosterkamp, J.; Hogewoning, S.W.; Harbinson, J.; van Ieperen, W. The responses of light interception, photosynthesis and fruit yield of cucumber to LED-lighting within the canopy. Physiol. Plant. 2010, 138, 289-300. [CrossRef] [PubMed]

15. Hernández, R.; Kubota, C. Physiological responses of cucumber seedlings under different blue and red photon flux ratios using LEDs. Environ. Exp. Bot. 2016, 121, 66-74. [CrossRef] 
16. Hernández, R.; Kubota, C. Growth and morphological response of cucumber seedlings to supplemental red and blue photon flux ratios under varied solar daily light integrals. Sci. Hortic. 2014, 173, 92-99. [CrossRef]

17. Brown, C.S.; Schuerger, A.C.; Sager, J.C. Growth and photomorphogenesis of pepper plants under red light-emitting diodes with supplemental blue or far-red lighting. J. Am. Soc. Hortic. 1995, 120, 808-813. [CrossRef]

18. Yorio, N.C.; Goins, G.D.; Kagie, H.R.; Wheeler, R.M.; Sager, J.C. Improving spinach, radish, and lettuce growth under red light-emitting diodes (LEDs) with blue light supplementation. HortScience 2001, 36, 380-383. [CrossRef]

19. Matsuda, R.; Ohashi-Kaneko, K.; Fujiwara, K.; Goto, E.; Kurata, K. Photosynthetic characteristics of rice leaves grown under red light with or without supplemental blue light. Plant Cell Physiol. 2004, 45, 1870-1874. [CrossRef]

20. Wang, Y.; Zhang, T.; Folta, K.M. Green light augments far-red-light-induced shade response. Plant Growth Regul. 2013, 77, 145-155. [CrossRef]

21. Golovatskaya, I.F.; Karnachuk, R.A. Role of green light in physiological activity of plants. Russ. J. Plant Physiol. 2014, 62, 727-740. [CrossRef]

22. Smith, H.L.; McAusland, L.; Murchie, E.H. Don't ignore the green light: Exploring diverse roles in plant processes. J. Exp. Bot. 2017, 68, 2099-2110. [CrossRef] [PubMed]

23. McCoshum, S.; Kiss, J.Z. Green light affects blue-light-based phototropism in hypocotyls of Arabidopsis thaliana. J. Torrey Bot. Soc. 2011, 138, 409-417. [CrossRef]

24. Frechilla, S.; Talbott, L.D.; Bogomolni, R.A.; Zeiger, E. Reversal of blue light-stimulated stomatal opening by green light. Plant Cell Physiol. 2000, 41, 171-176. [CrossRef] [PubMed]

25. Talbott, L.D.; Nikolova, G.; Ortix, A.; Shmayevich, I.; Zeiger, E. Green light reversal of blue-light-stimulated stomatal opening is found in a diversity of plant species. Am. J. Bot. 2002, 89, 366-368. [CrossRef] [PubMed]

26. Hemming, S.; Mohammadkhani, V.; Dueck, T. Diffuse greenhouse covering materials-Material technology, measurements and evaluation of optical properties. Acta Hortic. 2008, 797, 469-476. [CrossRef]

27. Hernández, R.; Kubota, C. Tomato seedling growth and morphological responses to supplemental LED lighting red:Blue ratios under varied daily solar light integrals. Acta Hortic. 2012, 956, 187-194. [CrossRef]

28. Sabir, N.; Singh, B. Protected cultivation of vegetables in global arena: A review. Indian J. Agric. Sci. 2013, 83, 123-135.

29. Savvides, A.; Fanourakis, D.; van Ieperen, W. Co-ordination of hydraulic and stomatal conductances across light qualities in cucumber leaves. J. Exp. Bot. 2012, 63, 1135-1143. [CrossRef]

30. Jinxiu, S.; Qingwu, M.; Weifan, D.; Dongxian, H. Effects of light quality on growth and development of cucumber seedlings in controlled environment. Int. J. Agric. Biol. 2017, 10, 312-318.

31. Shibuya, T.; Endo, R.; Yuba, T.; Kitaya, Y. The photosynthetic parameters of cucumber as affected by irradiances with different red:far-red ratios. Biol. Plant. 2015, 59, 198-200. [CrossRef]

32. Bergstrand, K.J.; Suthaparan, A.; Mortensen, L.M.; Gislerød, H.G. Photosynthesis in horticultural plants in relation to light quality and CO2 concentration. Eur. J. Hortic. Sci. 2016, 81, 237-242. [CrossRef]

33. Wang, X.Y.; Xu, X.M.; Cui, J. The importance of blue light for leaf area expansion, development of photosynthetic apparatus, and chloroplast ultrastructure of Cucumis sativus grown under weak light. Photosynthetica 2015, 53, 213-222. [CrossRef]

34. Emerson, R.; Chalmers, R.; Cederstrand, C. Some factors influencing the long-wave limit of photosynthesis. Proc. Natl. Acad. Sci. USA 1957, 43, 133-143. [CrossRef] [PubMed]

35. Hogewoning, S.W.; Wientjes, E.; Douwstra, P.; Trouwborst, G.; van Ieperen, W.; Croce, R. Photosynthetic quantum yield dynamics: From photosystems to leaves. Plant Cell 2012, 24, 1921-1935. [CrossRef]

36. Murakami, K.; Matsuda, R.; Fujiwara, K. A mathematical model of photosynthetic electron transport in response to the light spectrum based on excitation energy distributed to photosystems. Plant Cell Physiol. 2018, 59, 1643-1651. [CrossRef] [PubMed]

37. Baker, N.R. Chlorophyll fluorescence: A probe of photosynthesis in vivo. Annu. Rev. Plant Biol. 2008, 59, 89-113. [CrossRef]

38. Björkman, O.; Demmig, B. Photon yield of O2 evolution and chlorophyll fluorescence characteristics at $77 \mathrm{~K}$ among vascular plants of diverse origins. Planta 1987, 170, 489-504. [CrossRef] [PubMed]

39. Bergstrand, K.J.; Mortensen, L.M.; Suthaparan, A.; Gislerød, H.G. Acclimatisation of greenhouse crops to differing light quality. Sci. Hortic. 2016, 204, 1-7. [CrossRef]

40. Oxborough, K.; Baker, N.R. Resolving chlorophyll a fluorescence images of photosynthetic efficiency into photochemical and nonphotochemical components-Calculation of $\mathrm{qP}$ and $\mathrm{Fv}^{\prime} / \mathrm{Fm}^{\prime}$ without measuring Fo'. Photosynth. Res. 1997, 54, 135-142. [CrossRef]

41. Galka, P.; Santabarbara, S.; Khuong, T.T.H.; Degand, H.; Morsomme, P.; Jennings, R.C.; Boekema, E.J.; Caffarri, S. Functional analyses of the plant photosystem I-light-harvesting complex II supercomplex reveal that light-harvesting complex II loosely bound to photosystem II is a very efficient antenna for photosystem I in state II. Plant Cell 2012, 24, 2963-2978. [CrossRef]

42. Fujita, Y. A study on the dynamic features of photosystem stoichiometry: Accomplishments and problems for future studies. Photosynth. Res. 1997, 53, 83-93. [CrossRef]

43. Yamazaki, J.; Suzuki, T.; Maruta, E.; Kamimura, Y. The stoichiometry and antenna size of the two photosystems in marine green algae, Bryopsis maxima and Ulva pertusa, in relation to the light environment of their natural habitat. J. Exp. Bot. 2005, 56, 1517-1523. [CrossRef] 
44. Dietzel, L.; Bräutigam, K.; Pfannschmidt, T. Photosynthetic acclimation: State transitions and adjustment of photosystem stoichiometry-Functional relationships between short-term and long-term light quality acclimation in plants. FEBS J. 2008, 275, 1080-1088. [CrossRef]

45. Schöttler, M.A.; Tóth, S.Z. Photosynthetic complex stoichiometry dynamics in higher plants: Environmental acclimation and photosynthetic flux control. Front. Plant Sci. 2014, 5, 188. [PubMed]

46. Croce, R.; van Amerongen, H. Natural strategies for photosynthetic light harvesting. Nat. Chem. Biol. 2014, 10, 492-501. [CrossRef]

47. Schöttler, M.A.; Tóth, S.Z.; Boulouis, A.; Kahlau, S. Photosynthetic complex stoichiometry dynamics in higher plants: Biogenesis, function, and turnover of ATP synthase and the cytochrome B6f complex. J. Exp. Bot. 2015, 66, 2373-2400. [CrossRef] [PubMed]

48. Weraduwage, S.M.; Chen, J.; Anozie, F.C.; Morales, A.; Weise, S.E.; Sharkey, T.D. The relationship between leaf area growth and biomass accumulation in Arabidopsis thaliana. Front. Plant Sci. 2015, 6, 167. [CrossRef] [PubMed]

49. Casal, J.J.; Aphalo, P.J.; Sanchez, R.A. Phytochrome effects on leaf growth and chlorophyll content in Petunia axilaris. Plant Cell Environ. 1987, 10, 509-514. [CrossRef]

50. Jeong, H.W.; Lee, H.R.; Kim, H.M.; Hwang, H.S.; Hwand, S.J. Using light quality for growth control of cucumber seedlings in closed-type plant production system. Plants 2020, 9, 639. [CrossRef]

51. Paul, L.J.; Kurana, J.P. Phytochrome-mediated light signaling in plants: Emerging trends. Physiol. Mol. Biol. Plants 2008, 14, 9-22. [CrossRef] [PubMed]

52. Kahlen, K.; Stützel, H. Simplification of a light-based model for estimating final internode length in greenhouse cucumber canopies. Ann. Bot. 2011, 108, 1055-1063. [CrossRef]

53. Demotes-Mainard, S.; Péron, T.; Corot, A.; Bertheloot, J.; Le Gourrierec, J.; Pelleschi-Travier, S.; Crespel, L.; Morel, P.; HuchéThélier, L.; Boumaza, R.; et al. Plant responses to red and far-red lights, applications in horticulture. Environ. Exp. Bot. 2016, 121, 4-21. [CrossRef]

54. Arnon, D.I.; Hoagland, D.R. Crop production in artificial culture solutions and in soils with special reference to factors influencing yields and absorption of inorganic nutrients. Soil Sci. 1940, 50, 463-485.

55. Kramer, D.M.; Johnson, G.; Kiirats, O.; Edwards, G.E. New fluorescence parameters for the determination of QA redox state and excitation energy fluxes. Photosynth. Res. 2004, 79, 2019-2218. [CrossRef]

56. SAS Institute Inc. SAS Studio 3.8; SAS Institute Inc.: Cary, NC, USA, 2018.

57. Sharkey, T.D.; Bernacchi, C.J.; Farquhar, G.D.; Singsaas, E.L. Fitting photosynthetic carbon dioxide response curves for C3 leaves. Plant Cell Environ. 2007, 30, 1035-1040. [CrossRef]

58. Flexas, J.; Ribas-Carbo, M.; Diaz-Espejo, A.; Galmés, J.; Medrano, H. Mesophyll conductance to CO2: Current knowledge and future prospects. Plant Cell Environ. 2008, 31, 602-621. [CrossRef] [PubMed]

59. Jones, H.G. Plants and Microclimate, 2nd ed.; Cambridge University Press: Cambridge, UK, 1992; pp. 137-140. 